\title{
Does kV Image Guidance for Bone Metastases Improve Pain Control?
}

\author{
Ahmet S. Tunceroglu, ${ }^{1,2}$, Bin Gui ${ }^{2}$, Shou-En Lu ${ }^{3}$, Julian Sison ${ }^{2}$, Rahul Parikh ${ }^{2}$, \\ Sharad Goyal ${ }^{4}$, Bruce G. Haffty ${ }^{2}$, Sung Kim ${ }^{2}$ and Salma K. Jabbour ${ }^{2 *}$ \\ ${ }^{1}$ Department of Radiation Oncology, Metro Health Cancer Center, University of Michigan, Wyoming, MI, United States, \\ 2 Rutgers Cancer Institute of New Jersey, Rutgers Robert Wood Johnson Medical School, Rutgers University, New \\ Brunswick, NJ, United States, ${ }^{3}$ Rutgers School of Public Health, Rutgers University, Piscataway, NJ, United States, \\ ${ }^{4}$ Division of Radiation Oncology, The George Washington University Medical Faculty Associates, Washington, DC, \\ United States
}

\section{OPEN ACCESS}

Edited by:

William K. Small, Jr., Loyola University Chicago, United States

Reviewed by: Ima Paydar, Hospital of the University of Pennsylvania, United States Michael Charles Repka, Winthrop University Hospital, United States

*Correspondence:

Salma K. Jabbour jabbousk@cinj.rutgers.edu

Specialty section: This article was submitted to Radiation Oncology, a section of the journa

Frontiers in Oncology

Received: 08 November 2020 Accepted: 10 May 2021 Published: 17 June 2021

Citation:

Tunceroglu AS, Gui B, Lu S-E, Sison J, Parikh R, Goyal S, Haffty BG, Kim S and Jabbour SK (2021) Does KV Image Guidance for Bone Metastases Improve Pain Control?

Front. Oncol. 11:627282. doi: 10.3389/fonc.2021.627282
Purpose/Objectives: Despite its widespread availability, the use of kilovoltage ( $\mathrm{kV}$ ) image guidance is often related to factors such as perceived adequacy of clinical patient setup and individual practice patterns. We sought to determine whether $\mathrm{kV}$ image guidance in the treatment of painful bone metastases would improve therapeutic efficacy.

Materials/Methods: Under an Institutional Review Board approved protocol, hospital records of 164 patients having received radiation therapy to 257 individual painful osseous metastases were retrospectively reviewed. Marginal logistic regression analyses using the generalized estimating equation (GEE) approach were used to investigate potential associations between pain reduction and several patient, disease, and treatment related variables. Correlation of $\mathrm{kV}$ image guidance with pain reduction was analyzed by univariate and multivariate GEE logistic regression analysis.

Results: Median time to pain reduction was 3 days (range 0 109 days) from the start of radiation therapy. Pain reduction $\geq 50 \%$ was noted in 196 (77\%) metastatic lesions with 136 (53\%) demonstrating complete pain relief. Patients with metastatic lesions from nonsmall cell lung cancer experienced less pain relief $(p=0.007)$. Disease extension outside of bone was a negative predictor for pain reduction ( $p=0.02)$. On univariate and multivariate logistic regression, $\mathrm{kV}$ image guidance demonstrated a statistically significant correlation with improved pain control in cases involving treatment of the lower extremities $(p=0.03)$ and those with fewer treatment fractions $(p=0.01)$, particularly in the setting of extraosseous disease extension ( $p=0.003)$.

Conclusions: Kilovoltage image guidance in the treatment of painful bone metastases may offer greater pain control through improved patient setup, particularly for patients with tumors of the lower extremities, extraosseous disease extension, and fewer treatment fractions. 


\section{INTRODUCTION}

While long-term cure is the optimal outcome of radiation therapy (RT), many cancer patients will relapse and present with metastatic disease while others will be discovered to harbor widespread metastases at the initial presentation. In fact, the incidence of bone metastases have increased, believed to result largely from improved overall patient survival owing to improved cancer treatments $(1,2)$. Of the $1,806,590$ cases of cancer estimated for 2020 in the United States, over $40 \%$ will be of cancers that commonly metastasize to the bone including breast, prostate, lung, and kidney (3). Following lung and liver, bone is the third most common site of metastatic disease (2). Using MarketScan and Medicare databases, $\mathrm{Li}$ and colleagues estimated the prevalence of skeletal metastases to be approximately 280,000 patients per year - a figure that the authors concluded was likely an underestimate. Indeed, other estimates are closer to 400,000 patients (4-6). Furthermore, among patients with breast and prostate cancers, the bulk of the disease at the time of death typically will be in bone (4). Among patients with non-small cell lung cancer, Kuchuk et al. reported bone metastases at diagnosis in $20-40 \%$ of patients (7).

Cancer metastases to bone lead to a myriad of sequelae, or "skeletal-related events," for patients, their families, and the healthcare system. Pain, often intractable, is the most common clinical symptom associated with osseous metastases and the mechanisms responsible for the bone pain are poorly understood but appear to be related to osteolysis (4). This bone resorption can lead to the development of a pathologic fracture, a particularly worrisome complication, often in weight-bearing bones. Other manifestations of skeletal metastases include hypercalcemia, reduced mobility causing declines in performance status, neurologic deficits arising from nerve-compression syndromes such as spinal cord compression, reduced quality of life [i.e. reduced functional well-being, physical well-being, and emotional well-being $(8,9)]$, and death $(2,4,10,11)$. The effect of pathologic fractures on mortality is particularly troubling, as reports have suggested a $32 \%$ increased risk of death following non-vertebral fractures, and vertebral fractures have been associated with a $23-90 \%$ increased risk of mortality $(12,13)$.

Radiation therapy is a longstanding source of relief for painful bone metastases. As with any external beam radiation treatment, accurate and reproducible patient positioning is vital. Imageguided radiation therapy (IGRT) is among the available tools for achieving this accuracy, and serves an important role in modern RT, particularly in cases treated with curative intent. However, despite the widespread availability of IGRT techniques such as orthogonal kilovoltage $(\mathrm{kV})$ imaging, their use often depends on factors such as individual practitioner preferences, institutional practices, the perceived adequacy of clinical patient set up and prior authorization by insurance companies. We, therefore, sought to determine whether or not daily $\mathrm{kV}$ image guidance provided a therapeutic benefit in the palliative treatment of osseous metastases and which patient and disease related parameters predicted for this benefit. We hypothesized that a clinically relevant benefit of $\mathrm{kV}$ image guidance would be realized in cases presenting with extraosseous disease extension and in those involving treatment of sites that may be more difficult to reproducibly immobilize, such as the extremities.

\section{MATERIALS AND METHODS}

\section{Ethics}

The studies involving patient data were reviewed and approved by the Rutgers University Ethics and Compliance Committee.

\section{Patient Selection}

Under an Institutional Review Board-approved protocol, hospital records of 255 patients who received RT for bone metastases were retrospectively reviewed. All patients were treated between 2004 2015 at the Rutgers Cancer Institute of New Jersey and Rutgers Robert Wood Johnson University Hospital. Ninety-one patients were excluded because of the lack of recorded pain scores, incomplete RT records, inadequate post-treatment follow up, or death within 30 days of treatment completion due to progressive systemic disease. The final cohort consisted of 164 patients having received RT. Patient self-reported pre- and post-treatment pain scores were obtained for 257 individual osseous metastases.

\section{Data Collection}

Standard baseline evaluation included a complete medical history and physical, radiologic, and pathologic assessments. Data extracted from the charts included patient age, ethnicity, use of systemic therapy, histology, site of metastasis, prior surgical resection, extraosseous extension, and radiation treatment variables such as total dose, number of fractions, dose per fraction, and $\mathrm{kV}$ imaging. Patients treated with SBRT were excluded from the analysis. To gather information regarding pain response and time to response, charts were reviewed for pain at the following time points: the initial patient consultation for RT, the first ontreatment visit, halfway through RT, at the last on treatment visit during RT, and 4 weeks after RT completion at the first follow-up. Patients were asked to quantify their pain on the Numeric Pain Rating Scale ranging from 0-10, with 0 representing no pain and 10 indicating severe pain. This pain scale is widely utilized and has been validated as an easily applicable, sensitive and reproducible means of assessing pain (14).

At our institution, it is customary for all patients to undergo computed tomography (CT) simulation in order to obtain threedimensional anatomy to help define treatment fields and to develop a patient-specific treatment plan. Patient set up during simulation is performed according to institutional standards, with use of immobilization devices such as knee/foot locks as needed. After CT scan acquisition, images were transferred to the Varian Eclipse ${ }^{\mathrm{TM}}$ Treatment Planning System (TPS, version 7.3.10; Varian Medical Systems, Palo Alto, CA) where target delineation, isocenter placement, beam placement and treatment planning were performed. Whether or not the osseous gross tumor volume (GTV) was contoured and utilization of $\mathrm{kV}$ imaging during treatment delivery were based on provider preference. All patients for whom conformal treatment planning was used also 
received megavoltage (MV) portal imaging on the first day of treatment delivery and every five fractions.

\section{Statistical Analyses}

Reduction in patient self-reported pain scores following RT were analyzed in the context of the aforementioned patient, disease, and treatment related parameters. Pain reduction for each osseous metastasis, measured by comparing pre- and posttreatment Numeric Pain Rating Scale scores, was dichotomized by the median in the sample (i.e., $\Delta$ Pain $\leq 5$ vs. $\Delta$ Pain $>5$ ) to facilitate statistical data analysis. "Good pain response" was defined as $>5$ point decrease following RT and "poor pain response" was defined as $\leq 5$-point decrease. To account for potential correlation between pain scores from multiple metastases within the same patient, marginal logistic regression analyses using the generalized estimating equation (GEE) approach were performed. Specifically, bivariate analyses using GEE logistic regressions were performed to assess the association of individual factors with pain reduction. Variables demonstrating a significant association with pain relief $(\mathrm{p}<0.10)$ were subsequently used to build a multivariable logistic regression model based on the back-elimination principle. Significant factors in the multivariable model were defined by $\mathrm{p}<0.05$. Because $\mathrm{kV}$ imaging is a variable of interest, this variable was also kept in the back-elimination procedure during creation of the multivariable model. All statistical analyses were performed using SAS University Edition (SAS Institute Inc., Cary, North Carolina).

\section{RESULTS}

Of the initial 255 patients identified, 91 were excluded from the study, resulting in a final cohort of 164 patients treated for 257 osseous metastases. The median patient age was 64.5 years, with $45.1 \%$ males and $54.9 \%$ females. The most common histology was breast $(26.5 \%)$, followed by prostate $(23.7 \%)$, and non-small cell lung (23\%) cancers (NSCLC). Extraosseous disease was noted in $59.1 \%$. The most common sites of disease were the spine $(46.1 \%)$ and the lower extremities/pelvis (37.9\%). Additional baseline patient characteristics are described in Table 1. In $51 \%$ of osseous metastases, the physician contoured the GTV. Among those contoured metastases, the median GTV was $54.2 \mathrm{~cm}^{3}$ (range $0.04-1729 \mathrm{~cm}^{3}$ ).

A total of $46 \%$ of patients underwent at least one $\mathrm{kV}$ image during RT. Of the patients that underwent $\mathrm{kV}$ imaging, the mean number of fractions for which $\mathrm{kV}$ image guidance was utilized was $80 \% \pm 26.5 \%$, the median was $90 \%$, and the first and third quartiles were $70 \%$ and $100 \%$, respectively. The median total dose was 2750 cGy (range 300 3750 cGy) delivered over 10 fractions (range 1 17). The median of baseline reported pain score was 8 (range 1 10). For patients receiving 1-5 fractions, the median pain reduction was 5 (range -3 10) with a median interval of 2 days (range 0 94 days) from the start of treatment, while for patients receiving 6-10 fractions, the median pain reduction was 6 (range $0 \sim 10$ ) with a median interval of 10 days (range 0 109 days) from the start of treatment.
TABLE 1 | Baseline patient characteristics.

\begin{tabular}{|c|c|c|}
\hline Characteristic & Median & Range \\
\hline Age (y) & 64.5 & $30.8-87.1$ \\
\hline GTV volume $\left(\mathrm{cm}^{3}\right)$ & 54.2 & $0.04-1729.0$ \\
\hline Total fractions & 10 & $1-30$ \\
\hline Total dose (cGy) & 2750 & $300-3750$ \\
\hline Dose/fx (cGy) & 300 & $30-1600$ \\
\hline Pain reduction & 5 & $-3-10$ \\
\hline \% Pain reduction & 100 & $-300-100$ \\
\hline \multirow[t]{2}{*}{$\% \mathrm{kV}$ imaging } & 0 & $0-100$ \\
\hline & Frequency & $\%$ \\
\hline \multicolumn{3}{|l|}{ Histology } \\
\hline Prostate & 61 & 23.74 \\
\hline Breast & 68 & 26.46 \\
\hline NSCLC & 59 & 22.96 \\
\hline Small cell lung cancer & 3 & 1.17 \\
\hline Renal & 23 & 8.95 \\
\hline Bladder & 5 & 1.95 \\
\hline Esophagus/Gastric & 4 & 1.56 \\
\hline Melanoma & 9 & 3.5 \\
\hline Colorectal & 8 & 3.11 \\
\hline Sarcoma & 5 & 1.95 \\
\hline Myeloma/Lymphoma & 3 & 1.17 \\
\hline $\mathrm{HCC}$ & 1 & 0.39 \\
\hline $\mathrm{H} \& \mathrm{~N}$ & 4 & 1.56 \\
\hline Gyn & 2 & 0.78 \\
\hline \multicolumn{3}{|l|}{ Gender } \\
\hline Female & 141 & 54.86 \\
\hline Male & 116 & 45.14 \\
\hline \multicolumn{3}{|l|}{ ECOG Performance Status } \\
\hline 0 & 82 & 38.3 \\
\hline 1 & 69 & 32.2 \\
\hline 2 & 49 & 22.9 \\
\hline 3 & 13 & 6.1 \\
\hline 4 & 1 & 0.5 \\
\hline \multicolumn{3}{|l|}{ Post-operative RT } \\
\hline Yes & 25 & 9.73 \\
\hline No & 232 & 90.27 \\
\hline \multicolumn{3}{|l|}{ GTV contoured } \\
\hline Yes & 131 & 50.97 \\
\hline No & 126 & 49.03 \\
\hline \multicolumn{3}{|l|}{ Extension beyond bone } \\
\hline Yes & 152 & 59.14 \\
\hline No & 105 & 40.86 \\
\hline \multicolumn{3}{|l|}{ Disease site } \\
\hline Spine & 118 & 46.09 \\
\hline Upper extremities & 22 & 8.59 \\
\hline Lower extremities/pelvis & 97 & 37.89 \\
\hline Ribs/chest wall & 18 & 7.03 \\
\hline
\end{tabular}

92.6\% $(\mathrm{n}=238 / 257)$ of cases had any pain relief, $76.2 \%(\mathrm{n}=$ $196 / 257)$ had $\geq 50 \%$ pain relief, and $52.9 \%$ metastases $(n=136 /$ 257) achieved complete pain relief. One hundred metastases (38.9\%) received pain relief during treatment.

\section{Histology}

There was noted to be a significant difference in pain reduction among different types of cancer (Table 2 ). Specifically, pain due to metastatic lesions of NSCLC-origin was possibly less likely to demonstrate good response, compared to pain due to metastatic lesions of non-NSCLC origin $(\mathrm{p}=0.007)$. 
TABLE 2 | Differences in pain reduction according to parameters investigated.

\begin{tabular}{|c|c|c|}
\hline Parameter & $\begin{array}{l}\text { Absolute pain } \\
\text { reduction }\end{array}$ & $\begin{array}{c}P \\
\text { value }\end{array}$ \\
\hline Histology & & 0.007 \\
\hline NSCLC & $4(-3 \sim 10)$ & \\
\hline Other & $5(-2 \sim 10)$ & \\
\hline Age & & 0.94 \\
\hline$<65$ & $5(-3 \sim 10)$ & \\
\hline$\geq 65$ & $5(-3 \sim 10)$ & \\
\hline Gender & & 0.21 \\
\hline Male & $5(-3 \sim 10)$ & \\
\hline Female & $5(-2 \sim 10)$ & \\
\hline ECOG Performance Status & & 0.55 \\
\hline 0 & $5(-3 \sim 10)$ & \\
\hline 1 & $6(-3 \sim 10)$ & \\
\hline 2 & $5(-2 \sim 10)$ & \\
\hline 3 & $4.5(0 \sim 10)$ & \\
\hline 4 & $9(9 \sim 9)$ & \\
\hline Postoperative & & 0.74 \\
\hline Yes & $4.5(2 \sim 10)$ & \\
\hline No & $5(-3 \sim 10)$ & \\
\hline Extension beyond bone & & 0.23 \\
\hline Yes & $5(-1 \sim 10)$ & \\
\hline No & $6(-3 \sim 10)$ & \\
\hline Site & & 0.85 \\
\hline Spine & $5(-3 \sim 10)$ & \\
\hline Upper extremities & $5(1 \sim 10)$ & \\
\hline Lower extremities/pelvis & $5(-3 \sim 10)$ & \\
\hline Ribs/chest wall & $5(0 \sim 10)$ & \\
\hline Other & $2(2 \sim 2)$ & \\
\hline Total dose & & 0.23 \\
\hline$\geq 2800$ & $5(-3 \sim 10)$ & \\
\hline$<2800$ & $5(-2 \sim 10)$ & \\
\hline Dose/fx & & 0.26 \\
\hline >200 cGy & $5(-3 \sim 10)$ & \\
\hline$\leq 200$ cGy & $8(1 \sim 10)$ & \\
\hline Dose/fx & & 0.17 \\
\hline >300 cGy & $5(-3 \sim 10)$ & \\
\hline$\leq 300$ cGy & $5(-2 \sim 10)$ & \\
\hline Number of fractions & & 0.06 \\
\hline 1 & $3(-3 \sim 10)$ & \\
\hline$>1$ & $5(-2 \sim 10)$ & \\
\hline$\% \mathrm{kV}$ imaging & & 0.07 \\
\hline$<90$ & $5(-3 \sim 10)$ & \\
\hline$\geq 90$ & $6(0 \sim 10)$ & \\
\hline GTV contoured (entire cohort) & & 0.54 \\
\hline Yes & $5(-2 \sim 10)$ & \\
\hline No & $5(-3 \sim 10)$ & \\
\hline $\begin{array}{l}\text { GTV contoured (patients with extraosseous } \\
\text { disease extension) }\end{array}$ & & 0.55 \\
\hline Yes & $5(-1 \sim 10)$ & \\
\hline No & $5(0 \sim 10)$ & \\
\hline GTV volume $(n=131)$ & & 0.96 \\
\hline$\geq 55 \mathrm{~cm}^{3}$ & $5(-2 \sim 10)$ & \\
\hline$<55 \mathrm{~cm}^{3}$ & $5(-1 \sim 10)$ & \\
\hline
\end{tabular}

\section{Extraosseous Disease Extension}

Though a difference in absolute pain reduction was not detected between metastatic lesions with and without extraosseous extension ( $\mathrm{p}=0.23$ ) (Table 2), we did find a statistically significant difference when dichotomizing by pain relief of $\Delta 5$ points ( $p=0.03)$ (Table 3). Similarly, extension beyond bone was found to be the only significant factor negatively predicting for pain relief on multivariate regression analysis, with an odds ratio of 0.58 for $\Delta 5$-point pain reduction $(\mathrm{p}=0.02)$, suggesting less effective pain control among patients with extraosseous disease (Table 3). There were no differences in dose, number of fractions or dose per fraction between metastatic lesions with or without extension beyond bone ( $\mathrm{p}=0.37,0.91,0.99$, respectively).

\section{kV Imaging}

For the entire patient cohort, utilization of $\mathrm{kV}$ image guidance for $\geq 90 \%$ of the delivered fractions did not yield a statistically significant improvement in pain reduction $(\mathrm{p}=0.07)$. There was, however, a statistically significant improvement in pain response with $\geq 90 \% \mathrm{kV}$ imaging for treatments delivered to the extremities, with even greater significance for the lower extremities ( $\mathrm{p}=0.05$ and $\mathrm{p}=0.03$, respectively) (Table 4).

The benefit of $\mathrm{kV}$ imaging also appeared to be dependent on fractionation insofar that 10 fraction regimens appeared to derive no statistically significant benefit from $\mathrm{kV}$ imaging $(\mathrm{p}=$ $0.74)$ in contrast to 5 -fraction regimens $(\mathrm{p}=0.01)$ (Table 4$)$. The greater benefit of $\mathrm{kV}$ imaging in 5 -fraction as opposed to 10 fraction treatment courses was more pronounced for cases with extraosseous disease extension, $\mathrm{p}=0.86$ for 10 fractions and $\mathrm{p}=$ 0.003 for 5 fractions (Table 4). There were no statistically significant differences between patients receiving $\mathrm{kV}$ imaging for $<90 \%$ vs $\geq 90 \%$ of fractions with respect to age, total radiation dose delivered, histology, gender, extraosseous extension, or disease site (Table 5).

\section{Fraction Number}

The only condition in which we detected an effect of fractionation was among patients who received $\mathrm{kV}$ imaging for $<90 \%$ of fractions - in these patients, regimens consisting of $\leq 5$ fractions yielded less pain relief than those consisting of $>5$ fractions $(\mathrm{p}=$ 0.03) (Table 6).

\section{Time to Pain Reduction}

We hypothesized that in addition to overall pain reduction, the time interval between the start of palliative radiation and the realization of pain reduction may also be correlated with $\mathrm{kV}$ imaging and

TABLE 3 | Odds ratio for $\triangle 5$-point pain reduction.

\begin{tabular}{|c|c|c|c|c|c|c|}
\hline Parameter & \multicolumn{3}{|c|}{ Bivariate analysis } & \multicolumn{3}{|c|}{ Multivariable analysis based on backward elimination procedure } \\
\hline$\% \mathrm{kV}$ imaging & 0.84 & $0.51-1.39$ & 0.08 & - & - & 0.09 \\
\hline
\end{tabular}

The bold values denote $p$ values indicating statistical significance, i.e. $p \leq 0.05$. 
TABLE 4 | Effect of $\mathrm{kV}$ imaging on pain reduction by fraction number, disease site, and extraosseous disease extension.

\begin{tabular}{|c|c|c|c|}
\hline & \multicolumn{3}{|c|}{$\begin{array}{l}\text { Median of Absolute Pain } \\
\text { Reduction }\end{array}$} \\
\hline & $\begin{array}{c}\mathbf{k V} \\
\text { images } \\
<90 \%\end{array}$ & $\begin{array}{c}\mathbf{k V} \\
\text { images } \\
\geq 90 \%\end{array}$ & $\mathbf{p}$ \\
\hline All patients ( $\mathrm{n}=188$ vs 67 ) & 5 & 6 & 0.07 \\
\hline $\begin{array}{l}\text { All patients with total fraction }>1(n=171 \text { vs } \\
58)\end{array}$ & 5 & 6 & 0.07 \\
\hline Site = Spine ( $n=86$ vs 24) & 5 & 5.5 & 0.86 \\
\hline Site $=$ Lower extremities ( $n=59$ vs 26) & 5 & 6.5 & 0.03 \\
\hline $\begin{array}{l}\text { Site = Upper and lower extremities } \\
\text { ( } \mathrm{n}=73 \text { vs } 31)\end{array}$ & 5 & 6 & 0.05 \\
\hline Total fractions $=5(n=57$ vs 24$)$ & 5 & 6.5 & 0.01 \\
\hline Total fractions $\leq 5$ ( $n=78$ vs 38 ) & 4 & 5.5 & 0.05 \\
\hline Total fractions $>5(n=110$ vs 31$)$ & 5 & 6 & 0.64 \\
\hline Total fractions $=10$ ( $\mathrm{n}=77$ vs 22) & 5 & 6 & 0.74 \\
\hline Total fractions $\leq 10(\mathrm{n}=165$ vs 61$)$ & 5 & 6 & 0.19 \\
\hline Total fractions >10 ( $n=23$ vs 8) & 5 & 7 & 0.41 \\
\hline $\begin{array}{l}\text { Patients with extraosseous disease }(n=112 \\
\text { vs 39) }\end{array}$ & 5 & 5.5 & 0.37 \\
\hline Site = Spine ( $\mathrm{n}=58$ vs 20) & 5 & 5.5 & 0.42 \\
\hline Site $=$ Lower extremities ( $n=33$ vs 14) & 5 & 5 & 0.08 \\
\hline $\begin{array}{l}\text { Site = Upper and lower extremities ( } n=42 \text { vs } \\
\text { 18) }\end{array}$ & 5 & 5 & 0.10 \\
\hline Total fractions $=5(n=34$ vs 14$)$ & 4 & 7 & 0.003 \\
\hline Total fractions $=10(n=44$ vs 12) & 5 & 6.5 & 0.86 \\
\hline Patients with total fractions $=1$ ( $n=13$ vs 13 ) & 2 & 4 & 0.35 \\
\hline
\end{tabular}

The bold values denote $p$ values indicating statistical significance, i.e. $p \leq 0.05$.

fractionation, with faster pain relief through increased $\mathrm{kV}$ image guidance and hypofractionation, particularly for sites that may be more difficult to accurately set up on a daily basis, such as the spine or extremities. However, we were unable to detect any association between pain relief and $\mathrm{kV}$ image use or fractionation for any particular disease site or for patients with extraosseous disease spread (Table 7).

\section{GTV Contouring}

While some physicians routinely contour the GTV for palliative cases, this practice is not universal. We analyzed whether or not contouring of the target volume improved pain reduction both in the entire patient cohort, and as well as among patients with extraosseous disease extension. However, we did not detect evidence of greater pain relief with target volume contouring in either patient population (Table 2).

\section{DISCUSSION}

We report the findings of our analysis, which did detect a correlation between improved pain relief and $\mathrm{kV}$ imaging. As hypothesized, the benefit of $\mathrm{kV}$ imaging was realized most in cases involving treatment of the lower extremities, which might be expected to be difficult to reproducibly immobilize on a daily basis. We also report improved pain control with $\mathrm{kV}$ imaging,
TABLE 5 | Baseline patient characteristics with respect to kV image use.

\begin{tabular}{|c|c|c|c|}
\hline \multirow[b]{3}{*}{ Age (y) } & \multirow{2}{*}{\multicolumn{2}{|c|}{$\begin{array}{c}<90 \% \mathbf{k V} \text { imaging } \geq 90 \% \mathbf{k V} \text { imaging } \\
\text { Median }\end{array}$}} & \multirow{3}{*}{$\begin{array}{c}\text { P value } \\
0.92\end{array}$} \\
\hline & & & \\
\hline & 64.4 & 64.4 & \\
\hline \multirow[t]{2}{*}{ Total dose (cGy) } & 3000 & 2000 & 0.17 \\
\hline & \multicolumn{2}{|c|}{ Frequency } & \\
\hline \multicolumn{3}{|l|}{ Histology } & 0.07 \\
\hline Prostate & 50 & 11 & \\
\hline Breast & 42 & 26 & \\
\hline NSCLC & 45 & 14 & \\
\hline Small cell lung cancer & 1 & 2 & \\
\hline Renal & 19 & 4 & \\
\hline Bladder & 4 & 1 & \\
\hline Esophagus/Gastric & 2 & 2 & \\
\hline Melanoma & 9 & 0 & \\
\hline Colorectal & 3 & 5 & \\
\hline Sarcoma & 4 & 1 & \\
\hline Myeloma/Lymphoma & 2 & 1 & \\
\hline $\mathrm{HCC}$ & 1 & 0 & \\
\hline $\mathrm{H} \& \mathrm{~N}$ & 3 & 1 & \\
\hline Gyn & 2 & 0 & \\
\hline Gender & & & 0.15 \\
\hline Female & 98 & 43 & \\
\hline Male & 90 & 26 & \\
\hline Extension beyond bone & & & 0.82 \\
\hline Yes & 112 & 40 & \\
\hline No & 76 & 29 & \\
\hline Disease site & & & 0.98 \\
\hline Spine & 87 & 31 & \\
\hline Upper extremities & 16 & 6 & \\
\hline Lower extremities/pelvis & 70 & 27 & \\
\hline Ribs/chest wall & 13 & 5 & \\
\hline
\end{tabular}

TABLE 6 | Effect on pain relief of fractionation with respect to $\mathrm{kV}$ image use.

\begin{tabular}{lllllll}
\hline & \multicolumn{5}{c}{ Median of Absolute Pain Reduction } \\
\cline { 2 - 7 } & $\begin{array}{c}\mathbf{k V} \text { images } \\
\mathbf{< 9 0 \%}\end{array}$ & $\mathbf{p}$ & $\begin{array}{c}\mathbf{k V} \text { images } \\
\mathbf{9 0 0 \%}\end{array}$ & $\mathbf{p}$ \\
& 4 & 5 & $\mathbf{0 . 0 3}$ & 5.5 & 6 & 0.96 \\
All patients (fraction $\leq 5$ vs $>5$ ) & 4 & 5 & 0.36 & 6 & 7 & 0.18 \\
All patients (fraction $\leq 10$ vs $>10)$ & 5 & 5 &
\end{tabular}

The bold values denote $p$ values indicating statistical significance, i.e. $p \leq 0.05$.

TABLE 7 | Effect of kV imaging, fraction number and fraction size on time to pain relief.

\begin{tabular}{|c|c|c|c|c|}
\hline & $\begin{array}{l}\text { kV imaging } \\
p \text { values }\end{array}$ & $\begin{array}{c}\text { Fractionation } \\
\text { p values }\end{array}$ & $\begin{array}{c}200 \text { cGy/fx } \\
p \text { values }\end{array}$ & $\begin{array}{c}300 \text { cGy/fx } \\
\text { p values }\end{array}$ \\
\hline All patients & 0.19 & 0.22 & 0.95 & 0.95 \\
\hline Site = Spine & 0.44 & 0.53 & 0.87 & 0.41 \\
\hline $\begin{array}{l}\text { Site = Lower } \\
\text { extremities }\end{array}$ & 0.20 & 0.63 & 0.94 & 0.56 \\
\hline $\begin{array}{l}\text { Site = Upper \& } \\
\text { lower extremities }\end{array}$ & 0.32 & 0.75 & 0.96 & 0.83 \\
\hline $\begin{array}{l}\text { Patients with } \\
\text { extraosseous } \\
\text { disease }\end{array}$ & 0.86 & 0.28 & 0.80 & 0.68 \\
\hline
\end{tabular}


particularly in cases with fewer fractions (5 vs 10 fractions). This finding is not unexpected in that regimens with fewer total fractions would conceivably provide less opportunity to "compensate" for fractions with inaccurate positioning. We also report that pain due to metastatic lesions from NSCLC may be less likely to respond to RT as compared to other types of cancer.

Our study addresses the paucity of data with regard to the benefit of routine $\mathrm{kV}$ image guidance during conventionally fractionated RT, specifically in the setting of palliative radiotherapy for skeletal metastases. We report that RT remains a highly effective means of palliation for pain resulting from osseous metastases, with 93\% of patients reporting pain reduction and 53\% reporting complete pain relief. This is consistent with reports in the literature of complete pain relief ranging from 15 to $54 \%$ and partial pain relief ranging from 28 to $89 \%$ (15-20).

Notably, though the time interval between radiotherapy and pain relief is classically thought to be several weeks, we found the median time to any pain reduction to be 3 days from the start of treatment. We attempted to collect data on pain medication use; however, as this information was not consistently available and given the inherent uncertainly associated with retrospectively correlating pain scores with pain medication use, with other complicating factors such as consistency and schedule of their usage, this data was ultimately excluded from the final analysis. Though a formal statistical evaluation of pain medication use could not be completed, it is our institutional practice to maintain patients on their pretreatment pain regimen during palliative radiotherapy and, within our cohort of patients, we did not detect an overt increase in pain medication use following radiotherapy that could explain the significantly shorter time to pain relief in the current study.

Though we did not uncover a benefit of $\mathrm{kV}$ image guidance specifically with respect to cases with extraosseous disease extension, we did find that extraosseous disease extension was a significant negative predictor of pain reduction (Odds ratio 0.58 for $>5$-point pain reduction). This result may not be entirely surprising since disease extension beyond bony confines would be expected to result in significant pain and these patients, specifically, may consistently derive benefit from palliative radiotherapy, whether or not $\mathrm{kV}$ image guidance is utilized, provided that adequate margins and accurate patient set up are ensured. In support of this finding, we did find that the interaction between $\mathrm{kV}$ imaging and pain reduction following regimens consisting of fewer fractions was most significant in cases presenting with extraosseous disease extension. Although others have investigated the time burden of IGRT in the treatment of bone metastases (21), to our knowledge, the current study is the first to address the effect of IGRT on treatment efficacy.

While some physicians routinely contour the GTV for palliative cases, this practice is not universal. Though it was expected that contouring of the target volume would improve pain reduction, we did not detect evidence of greater pain relief with target volume contouring in either the entire patient cohort or the subgroup of patients with extraosseous disease extension.

The implications of this study are manifold. Procurement of $\mathrm{kV}$ images during treatment is a time-consuming process that places a demand on staff and equipment while also exposing the patient to additional radiation as well as increasing the risks associated with longer time on the treatment table. However, despite these potential drawbacks of $\mathrm{kV}$ image guidance, our study suggests that there may be certain patients for whom the benefits outweigh the risks.

Our findings suggest that while, for the majority of cases involving osseous metastases, palliative RT may be effectively delivered without the reliance on routine $\mathrm{kV}$ image guidance and without compromising efficacy, select groups of patients may be better served by incorporation of $\mathrm{kV}$ image guidance. Alternatively, and at a minimum, awareness of these difficult cases and mitigation of inaccurate treatment delivery through careful patient setup should be encouraged - this could prove to be useful information in countries lacking facilities capable of image guidance and in countries whose limited resources are taxed by sheer patient volume.

The current report is not without its limitations. Most significantly, the retrospective nature of our study inherently places restrictions on the conclusions that may be drawn. Additionally, while the present work suggests a possible added benefit of daily $\mathrm{kV}$ image guidance, this was in the setting of a large academic center with experienced radiation therapists trained in the utilization of $\mathrm{kV}$ image guidance for accurate treatment delivery. The importance of accurate patient set up cannot be overstated. Furthermore, it is conventional to apply generous field margins in palliative cases, which would certainly obviate the need for image guidance, but comes with the inevitable consequence of radiation delivery to healthy tissue. Our study did not examine the effect of margin size on the benefit of $\mathrm{kV}$ image guidance, and it may be that $\mathrm{kV}$ imaging is not necessary after a certain margin size. It is also conceivable, however, that radiation field margins may be reduced, in order to decrease normal tissue exposure, to a point at which $\mathrm{kV}$ image guidance for accurate daily patient set up becomes critical for all sites, especially in cases with extraosseous disease extension. Additionally, in our analysis we chose to dichotomize the use of $\mathrm{kV}$ image guidance according to the proportion of fractions in which it was utilized ( $\geq 90 \%$ vs $<90 \%$ ). The $90 \%$ cut-off value was chosen as it was the median percentage of fractions incorporating $\mathrm{kV}$ imaging. This value also made it possible to evaluate patients who received image guidance for nearly every fraction while making allowances for differences in physician practices, changes in institutional processes, and the retrospective nature of our study. Future work examining the effect of margin size on the benefit of daily $\mathrm{kV}$ imaging, the effect of $\mathrm{kV}$ imaging on duration of pain relief, as well as the minimum proportion of fractions that must be delivered with $\mathrm{kV}$ imaging in order to improve outcomes, may aid in clarification of the role of $\mathrm{kV}$ image guidance in the palliative setting.

\section{DATA AVAILABILITY STATEMENT}

The raw data supporting the conclusions of this article will be made available by the authors, without undue reservation. 


\section{ETHICS STATEMENT}

The studies involving patient data were reviewed and approved by the Rutgers University Ethics and Compliance Committee.

\section{AUTHOR CONTRIBUTIONS}

AT is the lead author of this manuscript and performed the majority of data collection and manuscript preparation. BG, SJ and JS assisted with data collection. All authors assisted with

\section{REFERENCES}

1. Weber KL, Randall RL, Grossman S, Parvizi J. Management of LowerExtremity Bone Metastasis. J Bone Joint Surg Am (2006) 88 Suppl 4:11-9. doi: 10.2106/JBJS.F.00635

2. Ibrahim T, Mercatali L, Amadori D. Bone and Cancer: The Osteoncology. Clin cases Miner Bone Metab (2013) 10(2):121-3.

3. Siegel RL, Miller KD, Jemal A. Cancer Statistics, 2020. CA Cancer J Clin (2020) 70(1):7-30. doi: 10.3322/caac.21590

4. Mundy GR. Metastasis to Bone: Causes, Consequences and Therapeutic Opportunities. Nat Rev Cancer (2002) 2(8):584-93. doi: 10.1038/nrc867

5. Li S, Peng Y, Weinhandl ED, Blaes AH, Cetin K, Chia VM, et al. Estimated Number of Prevalent Cases of Metastatic Bone Disease in the US Adult Population. Clin Epidemiol (2012) 4:87-93. doi: 10.2147/CLEP.S28339

6. Yu HH, Tsai YY, Hoffe SE. Overview of Diagnosis and Management of Metastatic Disease to Bone. Cancer Control (2012) 19(2):84-91. doi: 10.1177/ 107327481201900202

7. Kuchuk M, Addison CL, Clemons M, Kuchuk I, Wheatley-Price P. Incidence and Consequences of Bone Metastases in Lung Cancer Patients. J Bone Oncol (2013) 2(1):22-9. doi: 10.1016/j.jbo.2012.12.004

8. Weinfurt KP, Li Y, Castel LD, Saad F, Timbie JW, Glendenning GA, et al. The Significance of Skeletal-Related Events for the Health-Related Quality of Life of Patients With Metastatic Prostate Cancer. Ann Oncol (2005) 16(4):579-84. doi: 10.1093/annonc/mdi122

9. Lage MJ, Barber BL, Harrison DJ, Jun S. The Cost of Treating Skeletal-Related Events in Patients With Prostate Cancer. Am J Manag Care (2008) 14(5):317-22.

10. Coleman RE. Skeletal Complications of Malignancy. Cancer (1997) 80(8 Suppl):1588-94. doi: 10.1002/(SICI)1097-0142(19971015)80:8+<1588::AIDCNCR9>3.0.CO;2-G

11. Oefelein MG, Ricchiuti V, Conrad W, Resnick MI. Skeletal Fractures Negatively Correlate With Overall Survival in Men With Prostate Cancer. J Urol (2002) 168(3):1005-7. doi: 10.1016/S0022-5347(05)64561-2

12. Jalava T, Sarna S, Pylkkanen L, Mawer B, Kanis JA, Selby P, et al. Association Between Vertebral Fracture and Increased Mortality in Osteoporotic Patients. J Bone Miner Res (2003) 18(7):1254-60. doi: 10.1359/jbmr.2003.18.7.1254

13. Saad F, Lipton A, Cook R, Chen YM, Smith M, Coleman R. Pathologic Fractures Correlate With Reduced Survival in Patients With Malignant Bone Disease. Cancer (2007) 110(8):1860-7. doi: 10.1002/cncr.22991

14. Breivik H, Borchgrevink PC, Allen SM, Rosseland LA, Romundstad L, Hals EK, et al. Assessment of Pain. Br J Anaesth (2008) 101(1):17-24. doi: 10.1093/bja/aen103 manuscript preparation. S-EL provided statistical analysis. SJ is the corresponding author. The study was conceived by SJ. All authors contributed to the article and approved the submitted version.

\section{ACKNOWLEDGMENTS}

The work contained within this manuscript was completed during the first author's affiliation with the Rutgers Cancer Institute of New Jersey.

15. Tong D, Gillick L, Hendrickson FR. The Palliation of Symptomatic Osseous Metastases: Final Results of the Study by the Radiation Therapy Oncology Group. Cancer (1982) 50(5):893-9. doi: 10.1002/1097-0142(19820901) 50:5<893::AID-CNCR2820500515>3.0.CO;2-Y

16. Madsen EL. Painful Bone Metastasis: Efficacy of Radiotherapy Assessed by the Patients: A Randomized Trial Comparing 4 Gy X 6 Versus 10 Gy X 2. Int J Radiat Oncol Biol Phys (1983) 9(12):1775-9. doi: 10.1016/0360-3016(83) 90343-7

17. Price P, Hoskin PJ, Easton D, Austin D, Palmer SG, Yarnold JR. Prospective Randomised Trial of Single and Multifraction Radiotherapy Schedules in the Treatment of Painful Bony Metastases. Radiother Oncol (1986) 6(4):247-55. doi: 10.1016/S0167-8140(86)80191-8

18. Koswig S, Budach V. Remineralization and Pain Relief in Bone Metastases After After Different Radiotherapy Fractions (10 Times 3 Gy vs. 1 Time 8 Gy). A Prospective Study. Strahlenther Onkol (1999) 175(10):500-8. doi: 10.1007/ s000660050061

19. Wu JS, Wong R, Johnston M, Bezjak A, Whelan T. Meta-Analysis of DoseFractionation Radiotherapy Trials for the Palliation of Painful Bone Metastases. Int J Radiat Oncol Biol Phys (2003) 55(3):594-605. doi: 10.1016/ S0360-3016(02)04147-0

20. Chow E, Harris K, Fan G, Tsao M, Sze WM. Palliative Radiotherapy Trials for Bone Metastases: A Systematic Review. J Clin Oncol (2007) 25(11):1423-36. doi: 10.1200/JCO.2006.09.5281

21. Rief H, Habermehl D, Schubert K, Debus J, Combs SE. Time Evaluation of Image-Guided Radiotherapy in Patients With Spinal Bone Metastases. A Single-Center Study. Strahlenther Onkol (2014) 190(3):287-92. doi: 10.1007/ s00066-013-0494-z

Conflict of Interest: The authors declare that the research was conducted in the absence of any commercial or financial relationships that could be construed as a potential conflict of interest.

Copyright (c) 2021 Tunceroglu, Gui, Lu, Sison, Parikh, Goyal, Haffty, Kim and Jabbour. This is an open-access article distributed under the terms of the Creative Commons Attribution License (CC BY). The use, distribution or reproduction in other forums is permitted, provided the original author(s) and the copyright owner(s) are credited and that the original publication in this journal is cited, in accordance with accepted academic practice. No use, distribution or reproduction is permitted which does not comply with these terms. 